\title{
Perceptions of College Lecturers Regarding the Use of Performance Appraisal for Promoting Professional Development
}

\author{
Dr Miranda N. Mgijima \\ University of South Africa (UNISA), Dept. of Educational Leadership and Management \\ Email:mgijimm@unisa.ac.za,nomsomgjm4@gmail.com
}

Doi:10.5901/mjss.2014.v5n4p452

\section{Abstract}

Performance appraisal in the Further Education and Training Colleges cannot be an end in itself. The ultimate goal is to improve accountability and quality of learning outcomes. Using a systems theoretical perspective, this article examines the performance appraisal process in the colleges to determine the extent to which it is linked to professional development of lecturers. The performance of lecturers is pivotal in delivering the curriculum effectively. This article reports on selected findings based on the training needs assessment study conducted in 2012 using a mixed method approach and a purposive sampling technique. A total number of 373 lecturers and 80 managers participated in the study. The findings reveal major inconsistencies in the manner in which performance appraisals are conducted despite the fact that performance standards, instruments and criteria are prescribed in the national guidelines supplied by the Department of Education. The process is affected by subjectivity and lack of proper management control. It is concluded that these weaknesses undermine the very purpose for which performance appraisal was introduced. An overhaul of the current appraisal system is recommended in favour of a new system that is designed to suit the expectations and needs of these colleges.

Keywords: performance management; appraisal; professional development

\section{Introduction}

The past appraisal systems were more compliance-oriented. Today, the focus is on developing and supporting the professional growth of teachers (Figazzolo, 2013). A comprehensive performance and professional development framework puts emphasis on quality teaching as a powerful means of improving student outcomes (Australian Institute for Teaching and School Leadership, 2012). Similarly, linking different strands of teacher professionalism, namely, professional standards, induction, performance management and continuing professional development into a coherent cycle could raise standards and improve teaching (Walker, Jeffes, Hart, Lord, and Kinder, 2011; Evans, 2011). Bubb and Earley (2008) acknowledge that performance management, if conducted systematically, is an effective way of holding teachers to account for the quality of their teaching. The recommendation in their study is to link individuals' development to the analysis of needs through performance management and career development as well as self-evaluation and school improvement. Pedder, Storey and Opfer (2008) concur, arguing for a symbiotic approach that integrates strands of teachers' development, characterised by a strong correlation between performance management processes and opportunities for continuing professional development (in Walker, et al, 2011). However, Storey (2009) argues that the links between each of these strands are not yet fully understood and require further investigation.

This article seeks to examine how performance appraisals are conducted in the Further Education and Training (FET) colleges in South Africa. The key research questions are: what are the main purposes of the performance appraisal system in the FET colleges' sector? To what extent are the outcomes of performance appraisals used towards addressing professional development needs of college lecturers? The findings will contribute to the national discourse currently taking place regarding the need to initiate evidence based continuing professional development (CPD) programmes for FET college lecturers. The need for CPD is articulated well in the new Policy for Professional Qualifications of Lecturers in Technical and Vocational Education and Training (TVET) institutions issued by the Department of Higher Education and Training (DHET) in June, 2013.

\section{Performance Appraisals: Purpose and Use}

Debates about the use and usefulness of performance appraisal systems have been going on for the past two decades. 
Smith (2003) argues that "an effective performance appraisal should reward productive employees and assist professional growth and help inexperienced and unproductive employees to develop" (cited in Holi Ibrahim Holi Ali, 2012:199). Meyer maintains that a "properly designed and administered performance appraisal system can be a valuable tool for identifying the training and development needs of employees in an organisation" (2007:171). Grobler, Warnich, Carrell, Elbert and Hatfield (2002:319) concur, indicating that a "valid, job-related appraisal system will point out strengths and weaknesses in employee performance and may indicate training and development needs of employees". According to Dowling, Festing, and Eagle, a "key function of performance appraisal feedback is that it provides opportunities to improve performance gaps that might be eliminated with training and development" (2008:280). Performance appraisal is therefore an indispensable tool for creating effective $21^{\text {st }}$ century organisations.

The view expressed by Propper and Wilson is that "performance management may be undertaken at various levels and its purpose may differ depending on the level at which it is implemented" (2003:4). For example, Monyatsi, Steyn and Kamper outline three main purposes of performance appraisal: "to serve as a basis for modifying behaviour to realise more effective working habits; to provide adequate feedback to each employee on his/her performance; and to provide managers with data with which to evaluate future assignments and determine compensation" (2006: 427). In education, MacBeath (2012:58) confirms the growing popularity of performance appraisals and states that, "after decades of school effectiveness studies and the discovery that teachers make a difference, the focus of research turned to the teacher effect. Appraisal, evaluation and performance measures have been embraced by governments worldwide". The Education International (EI) Congress held in Cape Town in July 2011 "identified the evaluation of teachers as one of the key elements defining the broader context in which education workers will be operating in the future" $(O E C D$, 2013:8). The issue of performance appraisal system in the FET colleges is of significance and in line with the global effort to improve their effectiveness.

According to Bartlet (1998), the main aim of performance appraisal in an educational context is to increase quality assurance and monitor the work of teachers in order to manage the educational process even down to the classroom level (in Holi Ibrahim Holi Ali, 2012:199). Flores (2010:47), puts it more succinctly: "performance appraisal is done to improve teacher development and growth; identifying teachers' training needs and promoting excellence and quality of the service to the community". The Ontario Ministry of Education posits that performance appraisal is "to provide for fair, effective, and consistent teacher evaluation" (2002: 3). With the FET colleges struggling to shake off the bad image due to poor performance, importance of appraisals cannot be overemphasised. Evident from the literature is that the ability to highlight and act on staff development needs is regarded as the greatest asset of performance reviews.

Two perspectives tend to frame the discussion on teacher appraisal systems. First is the accountability view that Monyatsi, (2003: 66), perceives as "managerial, control-oriented, judgemental and hierarchical". The previous inspectorate system of the apartheid era in South Africa is believed to resemble this model. Secondly, the developmental perspective "gives the employee the primary responsibility to identify aspects in which development is desirable, separate from the processes of promotion and reward" (Simmons and lles, 2001: 6). However, Flores [2010:41] states that literature "identified the tensions between formative (oriented towards development) and summative purposes (linked to accountability and managerial decisions) of performance appraisals". A developmental and growth focused appraisal process stresses the importance of a dialogue between the parties involved to address the professional development needs of the appraised. By so doing, a direct link between performance appraisal and professional development is established. Instead of polarising the issues, perhaps it is best to consider the main purposes of performance appraisal as points along a continuum, with accountability at one end and appraisal for development at the other. Depending on the value attached, in-between performance appraisals could serve a variety of other purposes, such as providing for incentives and rewards, promotions and career mapping.

According to Bach (2000), the difficulty arises when different elements of appraisal are blended together in an illdefined manner where the appraiser is forced to adopt conflicting roles, cast as both a monitor and judge of performance and also as an understanding counsellor where guidance is required. Beer (1981) also noted that the multiple and potentially conflicting objectives employers seek in appraisal schemes account for many of the implementation difficulties that arise for them in their use. Other problems associated with performance appraisal include subjectivity and biasness among appraisers, as well as inconsistent and unreliable assessments. These are seen as causing stress, demotivation and aggression among the appraised. To caution, Saleh writes that "appraisals are generally considered to have a positive influence on performance, but, they also may have a negative impact ... when they are poorly designed or administered" (2008: 8).

Giving meaningful feedback is critical for successful performance appraisals. Performance feedback ought to convey information "about the quality of teacher performance, helping them improve and holding them accountable for 
their work" (Stronge, 2006b in Flores, 2010:43). The significance of feedback is at two levels. To those appraised, feedback conveys the view of the appraiser about the extent to which goals are met. At the organisational level, feedback is a communication platform about the strategic direction, goals and vision that everyone should aspire to. Feedback is said to increase commitment and motivation among the appraised, because it makes them feel like valuable members of the organisation.

The above discussion underscores the importance of exploring the linkages between appraisals and improvements in performance, an area identified as a major gap in the research conducted to-date on the FET colleges' sector. Central in the investigation is the issue of the dual purpose of performance appraisals and whether or not it has created any difficulties in fostering the link with professional development. A synopsis of the performance management system for FET colleges is necessary to contextualise the research problem.

\section{Performance Appraisal System in the Colleges}

The FET colleges are located at the nexus between the schooling system, universities and the workplace. The Integrated Quality Management System (IQMS) was introduced in schools as part of the system-wide reforms to transform education in post- apartheid South Africa. The IQMS is underpinned by the democratic principles of transparency, fairness, justice and equity. It was introduced in terms of Schedule 1 of the Employment of Educators Act that mandates the Education Minister to determine standards against which the performance of educators is evaluated (Government of South Africa, No.76 of 1998). Originally, three separate programmes existed, namely, the Developmental Appraisal System (DAS), the Whole-School Evaluation Policy (WSE) and the Performance Measurement (PM) system. These were subsequently combined to form the IQMS. In 2005, the IQMS was adapted for use in public FET colleges. This version consists of the developmental appraisal (DA) and the performance measurement (PM) programmes but excludes the WSE.

The IQMS is a regulated function. Formal performance reviews happen at defined intervals and are mandatory. The IQMS policy lists up to 13 standards against which the performance of lecturers is appraised. Standardised instruments and a personal growth plan (PGP) template for lecturers to record their training needs are provided. Lesson observations, perusal of student records, and self-assessment evidence compiled by the lecturer are some of the appraisal activities. Providing feedback is a requirement.

The IQMS has two main purposes. The developmental appraisal (DA) programme is used to determine areas of strength and weakness, and to draw up programmes for professional development. The performance measurement (PM) programme evaluates individual lecturers for salary/grade progression, affirmation of appointments, rewards and incentives. It is expected that both programmes should be implemented in an integrated way to ensure optimal effectiveness and co-ordination. However, their separate purposes are to be maintained (Department of Education, 2005). The IQMS therefore has dual, but complementary purposes. Although the IQMS is prescribed by the national Department of Education, the implementation process is managed internally by the college principals. Structures that support implementation are: the Senior Management Team (SMT), the College Staff Development Team (ColSDT) and the Development Support Group (DSG). Thus, the functions, roles and responsibilities associated with performance appraisals are distributed across different role-players who occupy different levels within the college hierarchy.

Performance management is embedded within the broader systemic reforms to transform the FET college sector. Because introducing change in one part of the system inevitably affects the other parts, successful implementation requires a network of interactions between these different parts. This underlines the importance of looking at the IQMS processes holistically, using the systems theoretical perspective.

\section{Theoretical Perspectives}

The systems theory states that any given system involves several components that are dependent and connected to each other (Bertalanffy, 1968; Hutchins, 1996). Among the first pioneers of the systems theory is the $18^{\text {th }}$-century German philosopher Hegel who stressed that the parts of a system are dynamically interrelated and cannot be understood in isolation from the whole. Watson and Reigeluth (2008), state that systems theory was formally conceived in the mid-twentieth century by a multi-disciplinary group of researchers, including Bertanlanffy (1968), who shared the perspective that science had become reductionist and the various disciplines isolated. Accordingly, the systems theory recognises the primacy of organising relationship processes between entities (of systems) while emphasising a strong need for coordination, integration and alignment of interrelated and interdependent processes that take place at the 
various levels of the system. Complexities in terms of purposes, processes and impact seem to characterise a number of systems. The systems perspective permits insight into the "what" as well as the "how" of the phenomenon (Banathy and Jenlink, 1996; Reigeluth, Banathy, \& Olson, 1993).

In this article, the investigation of the performance appraisal system occurs from a change process dimension. According to Watson, Watson and Reigeluth (2008), systemic change is the process of changing a system from one paradigm to another by applying systems thinking and systems theory. In their view, systemic change is concerned with the creation of a completely new system rather than a mere retooling of a current system. The IQMS replaced the old inspection system. Its implementation pervades all levels of the system, namely, the classroom, the college, the district/provincial office and the national level. As such, the central concern in the discussion is that of consistency of application at the different sites of the college system and between the college sub-system and the supra-system (national level). The problem is conceptualised not as a whole (education system reform) to be taken apart, but as a part (performance appraisal) of the larger whole. Performance appraisal is analysed in terms of its purpose and the role it has in the larger context of promoting quality and accountability through professional development of lecturers. The policy behind the performance appraisal system is determined at the national level but its operationalization is left to the colleges. It is the interplay of complex relational aspects between a new national policy directive, that prescribes what is to be done and the implementation process (the how) influenced by the environmental factors at the college level that has caused a disequilibrium in the system.

As institutions, the FET colleges are open social systems. Open systems adapt to environmental changes and in a changing environment this becomes a continuous process (Banathy and Jenlink, 1996: 44). Major reforms have been introduced into the FET colleges and the transformation process is on-going. Examining the functioning context of the education system in light of these changes is a part of this investigation. According to Ackoff and Emery (1972: 218), "the state of the part can be determined only in reference to the state of the system. The effect of change in one part or another is mediated by changes in the state of the whole". Given that the IQMS is a complex set of interdependent and interacting activities such as its policy design, planning and capacity building, training and resource allocation, administration of instruments, communicating feedback, deciding on rewards/incentives and advancing professional growth and development, this requires coordination and integration of these interdependent activities across all system levels. The systems theory emphasises the importance of integration, interrelatedness and interdependencies of the different components of the system, to avoid fragmentation and lack of synergy.

At the macro-level of the system, performance management is influenced by government policy. The national government ought to play an oversight role during implementation to ensure consistency in the application of the IQMS processes. Furthermore, the macro-system needs to ensure consistency of messages and information about performance management as well as clarifying roles and responsibilities through the value chain. At the provincial level, the administrators need to support the implementation of the IQMS policy, and continuously monitor the performance management activities carried out by the colleges and take remedial action where necessary. At college level, the principals should establish viable appraisal conditions and secure the quality of appraisal procedures. Thus, principals need to put reliable control measures in place to ensure that credible performance appraisals are conducted efficiently and effectively. Quality feedback is of essence for planning professional development programmes. The success of the principals in carrying out these responsibilities depends on the nature and amount of support received from the provincial and national offices. In this regard, performance appraisals should be orchestrated into a coherent operation to ensure a consistent and an equitable process across all levels of the system.

A reciprocal relationship between the college, the provincial and the national level needs to be nurtured for effective management of performance appraisals. Depending on whether colleges are convinced that the macro-system is doing its maximum to provide direction and support, colleges may not feel an obligation to reciprocate through hard work, loyalty and commitment. To emphasise, Magolis (2010) states that the performance of the system depends on how the elements work together and not how each element works independently. As Banathy and Jenlink (1996: 47) argue, systemic "educational change will become possible only if the educational community will develop a systems view of education, if it embraces the systems view and if it applies the systems view in its approach to change". This inquiry is guided by a combination of elements from a functions/structure and process models of a social system. The evidence on the process of IQMS implementation will elucidate what the successes are and where the weaknesses lie. Before presenting the evidence the method of inquiry is discussed. 


\section{Research Methodology}

This article reports selected findings from a large scale survey of the training needs of lecturers teaching fundamental subjects in the FET colleges. This study, led by the author assisted by a senior researcher and two data analysts, was commissioned in 2012 by the South African College Principals' Organisation (SACPO). The study used the mixed method approach for "purposes of breadth and depth of understanding and corroboration" (Johnson, Onwuegbuzie and Turner, 2007:123). The aim was "to produce a more complete picture by combining information from complementary kinds of data or sources" (Denscombe, 2008:272). This was to secure an in-depth understanding of performance appraisal practices in the colleges, while also focusing on how performance appraisals link with professional development of lecturers. A review of official government documents and existing literature from national and international studies on the topic was also conducted.

\subsection{Instruments}

Three questionnaires were developed. Tool A was for the curriculum management teams. Tool B was for subject lecturers. These were self-administered at each of the fifty colleges. Then, Tool C, a semi-structured questionnaire, was used during focus group discussions with subject lecturers and managers. These different sources of data enabled a reasonable degree of triangulation. The fourth, Tool D for college principals and campus managers was administered in the Eastern Cape only. To maintain focus on the perceptions of lecturers, data from Tool D are excluded in the analysis.

\subsection{Sampling}

Purposive sampling was followed. The aim was to include all fifty FET colleges in the study. Four lecturers, one for each of the four fundamental subjects on the National Curriculum, Vocational (NCV) programme were targeted. In addition, the manager responsible for the programme from each college was included in the sample. Table 1 below shows the actual sample obtained. Once submitted, the questionnaires were prepared for data entry, coding and for capturing. All questionnaires were checked for completeness before coding. Data was captured on EXCEL spread-sheets. The SPSS programme was used for processing the quantitative data. Partially filled or questionnaires with non-essential information were discarded. From the qualitative data, themes were derived and data categorised accordingly.

\section{Findings}

The overarching aim of this inquiry is to explore how performance appraisals are conducted and the extent to which the outcomes of appraisals link with professional development efforts to improve performance of lecturers. The questionnaires solicited information on such aspects as the process and frequency of appraisals; procedures followed when conducting appraisals; participation by different role-players; views on the value and use of feedback. These are discussed in detail later. First the response rate on the questionnaires is presented in Table 1.

Table 1: Questionnaire Returns

\begin{tabular}{|c|c|c|c|}
\hline Questionaire & Target & Expected Returns & Actual Returns \\
\hline Tool B & Lecturers & 200 (4 from each college) & 383(in the 4 subjects) \\
\hline Tool C & Lecturers & 121 & 121 \\
\hline Tool A & Managers & 50 (1 from each college) & 80 \\
\hline Tool D & EC Managers & 35 & 35 \\
\hline
\end{tabular}

The actual returns exceeded the target because FET colleges have multi-campuses and the NCV programme may be offered in more than one campus.

The main rationale behind this training needs assessment study was to determine in which competency areas lecturers needed professional development. The concern is the wide-spread problem of either unqualified or underqualified lecturers which is believed to be having an adverse effect on the quality of teaching and learning and, therefore, the major cause of poor student performance. Table 2 below reflects progression and throughput rates among students studying the fundamental subjects on the NCV programme. 


\subsection{Student Progression in the Four Subjects}

The profile of the student body in the FET colleges is very complex because of diverse academic backgrounds. Some pass grade 9 and move into an FET college. Others have either attempted or passed grade 12 while there are those mature students who having been already working, decide to study for a formal qualification. On the NCV programme, English and Life Orientation are compulsory for all students and they have a choice between Mathematics and Mathematics literacy. There is a notable wastage among students as they move from one level to the next. The table below shows the progression rates of students in each of the subjects in the years 2010 to 2011.

Table2: Student progression by subject - 2010 to 2011

\begin{tabular}{|l|c|c|}
\hline \multirow{2}{*}{ Subjects } & \multicolumn{2}{|c|}{ Progression Rates (\%) from 2010 $\rightarrow$ 2011 } \\
\cline { 2 - 3 } & Level $\mathbf{2} \rightarrow$ Level 3 & Level $\mathbf{3} \rightarrow$ Level 4 \\
\hline English & 41 & 35 \\
\hline Mathematics & 49 & 52 \\
\hline Math Literacy & 39 & 36 \\
\hline Life Orientation & 45 & 45 \\
\hline
\end{tabular}

While these values are very low, indicating high drop-out rates, they may even be lower if repeaters were excluded. The values in the table above show English and Mathematical Literacy with lowest progression rates followed by Life Orientation. Mathematics appears as having the highest progression rate. However it should be noted that students who register for mathematics would be students who are enrolled for mathematics related fields (such as Engineering Studies) where the entry requirement is higher. One can then conclude that teaching and learning in these four subjects is of poor quality, making it absolutely necessary to establish an effective appraisal process that provides a sound diagnosis of areas where lecturers require training and development. The quality of the lecturer has often been blamed for poor student performance.

Over the years, the initial preparation of college lecturers has been erratic and uncoordinated. Some lecturers have academic university degrees or advanced university level teaching qualifications, while others only have an end-ofcollege certificate, known as the N6 certificate. In between, a large number of lecturers hold diplomas/degrees without any professional qualifications. This has dire consequences for the achievement of learning outcomes (Mgijima and Morobe: 2012; Mgijima, 2013). The Developmental Appraisal (DA) aspect of the IQMS was conceived with the aim of appraising individual educators to determine areas of strength and weakness, and to draw up programmes for individual development. A constant review of lecturer performance is therefore essential in establishing a systematic process of planning training and development programmes of college lecturers. A look at the purposes of the IQMS will shed light on whether appraisals are perceived as making a meaningful contribution to professional development of lecturers.

\subsection{Performance appraisals and rewards}

Generally, performance appraisals may yield intrinsic and/or extrinsic rewards. As already established, the performance measurement (PM) component seeks to evaluate individual lecturers for salary/grade progression and for affirmation of appointments. When lecturers were asked why they thought the IQMS was introduced, almost 100\% of respondents reported that it was for the salary notch increase, with a few saying it was for pay progression that they qualified for. The lecturers claimed this happens largely without any structured feedback from performance reviews. Yet the IQMS policy requires appraisers to provide the appraised with feedback on areas where performance is found to be good or where weaknesses have been identified.

In the focus group discussions, some lecturers indicated that they automatically received a salary increase by virtue of having "filled the appraisal forms even if classroom observation is not done". Others voiced mixed opinions about the "wisdom of using performance appraisal results for salary increases". About $84 \%$ of the managers confirmed that awarding a $1 \%$ salary increase was the main outcome of the performance appraisal. Thus, linking pay decisions (the extrinsic reward) with appraisal appears to be the most popular reason behind the IQMS.

However, without structured feedback, it is unclear how these pay decisions are made. Normally, incentives are meant to reward achievement of specific performance goals. Measurement is usually expressed in terms of an overall or summative rating that must be discussed with the appraisee. The IQMS has predetermined rating scales. All that the appraisers do is to tick the relevant boxes. This often gives rise to problems in terms of the validity and accuracy of such 
ratings. Without a consistent method of arriving at summative scores, PM becomes highly problematic. The above finding reveals some of the weaknesses inherent in the PM process. We turn now to look at the intricate processes of developmental appraisal.

\subsection{Appraisal results and professional development}

Developmental appraisal is conducted to determine areas of strength and weakness, and to help draw up professional development programmes. Lecturers were required to attach their Personal Growth Plans [PGPS] when returning the questionnaires. The analysis of the plans resulted in a list of priority areas where the majority of lecturers indicated they needed training. It is a legitimate expectation that once identified their specific training needs would be addressed. This constitutes the intrinsic reward from which lecturers ought to benefit. Table 4 below summarises actions taken after appraisals have been conducted:

Table 4: Percentage of lecturers commenting about use of IQMS results

\begin{tabular}{|c|c|c|}
\hline $\begin{array}{c}\text { Lecturers sent for short } \\
\text { training courses }\end{array}$ & $\begin{array}{c}\text { Results are used by senior lecturer to provide } \\
\text { relevant assistance }\end{array}$ & $\begin{array}{c}\text { Results filed and no assistance to } \\
\text { improve on weaknesses }\end{array}$ \\
\hline $20 \%$ & $25.5 \%$ & $53 \%$ \\
\hline
\end{tabular}

Source: Mgijima (2013)

That $53 \%$ of respondents said their documents are filed and no assistance given to help improve on weaknesses is a serious concern. During the focus group discussions, one lecturer remarked that the opportunities for them to enhance their skills and competence were "pathetically limited". The $20 \%$ of respondents who are sent out for short course training indicated that the training did not target the specific areas of weakness as listed in their PGPs. Effectively, this implies that only about $25.5 \%$ of the respondents believe they meaningfully benefitted from the performance appraisal process although the impact of assistance from senior lecturers is yet to be assessed (Mgijima, 2013).

Emerging from the focus group discussions was that only to a small extent were appraisal outcomes discussed between lecturers and appraisers. The majority claimed never to have received either a verbal or a written report after being appraised. As a result they were not sure in what areas their performance was found either to be satisfactory. They contended that performance appraisal for them was a mere formality, and therefore a waste of time more so that the financial reward was reduced from $3 \%$ to $1 \%$. It can thus be deduced from the evidence above that there is no deliberate effort to link the appraisal process and the planning of professional development programmes. This is a deviation from the core objectives of the DA programme. This further reduces the usefulness of appraisals and diminishes the possibility of enhancing performance improvement among lecturers. Whilst about $2 \%$ in the sample reported that they had not undergone any performance appraisal in 2011, the majority of the lecturers in the focus groups felt that the current system is less than adequate for purposes of responding to their developmental needs. Given these findings, the IQMS has become a highly skewed process, lacking a balance between developmental and accountability purposes. This suggests the manner of conducting appraisals as the main cause.

\subsection{Appraisal procedures and activities}

Almost all respondents acknowledged the existence of standardised IQMS instruments. However, probing during focus group discussions on how these instruments were used revealed differing views on the IQMS activities and procedures. Regarding activities, the majority of the respondents mentioned as most common self-evaluation and classroom observation, whilst only a few listed peer interviews and perusal of student achievement results. Only about $6 \%$ of respondents mentioned the use of portfolios of evidence on moderation and or reviews of subject files as additional sources of information required by the appraisal teams. On classroom observations, one lecturer remarked during focus group discussions that instead of giving us guidance, "the assessment of lessons is about ticking a box exercise that is not helping us to improve teaching". This evidence shows that there is little consistency in the manner in which performance appraisals are conducted. There was also no evidence that the instruments are applied rigorously, fairly and consistently across the colleges.

Furthermore, lecturers were asked to comment on how and when they got feedback after appraisals. The focus 
group discussions indicated that providing feedback did not happen in a systematic manner. Despite the prescribed manner of giving feedback, scheduling feedback meetings was done at the discretion of individual supervisors or appraisal teams. Lecturers said feedback sessions were sporadic. One respondent attested, "it could be months before we received any feedback, depending on the workload of seniors at the time". From the survey, about $88 \%$ of respondents claimed that they had not yet received feedback from their supervisors (excluding salary adjustments) after the performance appraisals conducted in 2011. During the discussions, lecturers pointed out that the multiple structures involved in performance appraisals weakened the control of the process by the college principal which compromised quality and consistency. Although some lecturers and managers agreed that the IQMS was of some benefit, others raised concerns about the real purpose and method of appraisals.

In the focus group discussions, lecturers were quite vocal about their fear of coercive control of the appraisal process by some supervisors. They indicated that the IQMS "was open to abuse by the seniors". They noted bias and subjectivity when scoring was done and felt that extra pressure was put on them when they have to prepare documentation for appraisals because they were "not always prepared". A common comment from both lecturers and managers during the discussions was that lecturers think appraisals cause demotivation and low morale because there was no help afterwards. It was also claimed that after appraisal there was no clear procedure for follow up and support.

None of the respondents understood the role of provincial officials during performance appraisals despite it being a policy requirement that these officials should support and monitor the IQMS process. Also, there were no external moderation procedures in place. In fact, there is no evidence of involvement by provincial or national departmental officials in the appraisal processes whatsoever. The lecturers also thought the IQMS structures were not effective. This seems to have severely affected the credibility of the IQMS process with some saying the track record of the IQMS in the colleges is not impressive. Others perceived its implementation as having serious flaws. As a result they regarded the IQMS as a mere compliance issue that was unimportant for their career goals.

\section{Discussion}

These findings imply that arrangements for IQMS could be somewhat ad hoc, failing to link sufficiently the strategic goals of the college sector with personal development plans of lecturers as originally envisaged in the policy. Partly, the evidence points to a disjuncture between the policy intents and what has become of the IQMS in practice. There seems to be a great deal of confusion about the process, ending with a watered down version of the IQMS.

Distinctions between performance measurement and developmental appraisals were noted. The IQMS policy regards both as equally important but tensions between them are not effectively managed. It is evident that operating a performance appraisal system is complex. Failure to apply systems thinking during the design and implementation stages seems to have contributed to the current challenges, making the IQMS less successful. This assertion also indicates failure on the part of policy makers to generate confidence for the introduction of the IQMS through their oversight function.

Barring the few and minor changes effected, colleges are using an IQMS version that was originally designed for schools. Its fitness for purpose is therefore questionable. Furthermore, performance appraisal is a bureaucratic exercise that relies on standardised measures. This means that there is no flexibility to accommodate the different contexts and historical backgrounds of the colleges. The ineffective or limited control by college principals means there is no safeguarding quality and consistency of the IQMS process.

The use of multiple role-players in performance appraisals has created room for a wide variation in the application of procedures and instruments due to lack of monitoring and moderation by the departmental officials. Yet the use of teams in appraisals, if done procedurally, could enhance collegiality, collaboration and team work through exchange of advice and mutual support. It would enhance better dialogue and openness between lecturers and the appraisers, thereby enabling lecturers to become more actively involved in their appraisals.

Taking cognisance of the dual purpose of the IQMS, findings reveal that performance measurement for pay decisions takes precedence over the developmental objectives. For example, assessment of performance to see whether standards are met is not done, whilst appraisal for developmental purposes is grossly neglected. Focusing on pay decisions only gives a lopsided view of the IQMS making it inconsistent with its own objectives. Yet, the purpose of the IQMS is to hold individual lecturers accountable for student achievement whilst also responding to their identified development needs. It is indeed imperative that a performance appraisal system be well-balanced to achieve both purposes. 


\section{Conclusion}

In light of the above discussion, it may not be far-fetched to argue that the majority of participants regard the performance appraisal system as ineffective. Whilst the intentions of the IQMS are good, the findings unequivocally show that the flaws are in the design and in the implementation processes of the IQMS. In terms of its design, the IQMS is a multifaceted and complex programme that is not well-understood in the Further Education and Training colleges. The analysis shows that the manner of its implementation is inconsistent and its efficacy value is low, both emanating from its dual purpose, poor use of professional standards to measure performance, and lack of management control to conduct effective appraisals. From the systems theoretical perspective, the contention is that given the findings, the challenges are serious and require more than minor adjustments or amendments.

The greatest weakness is that a narrow traditional view that favours pay decisions has taken precedence over the strategic approach of conducting performance appraisals for promoting professional development. This is antithetical to the core objectives of the IQMS. As a result, appraisals are counter-productive and do not lead to excellence in performance. The appraisal results cannot be regarded as reliable and valid, nor as relevant and accurate. This makes it difficult to even determine the professional competency of lecturers. In view of this, the IQMS therefore, serves no real purpose in determining the professional development needs of the vast majority of the lecturers participating in the research. Corrective measures are needed to redirect the IQMS to the desired outcomes.

\section{Recommendations}

Performance appraisal and subsequent CPD is an investment that can help FET colleges stimulate lecturer development and maximise performance excellence. Colleges need a robust performance appraisal system that is synergistically aligned horizontally with the sector strategy and vertically integrated to the national goals. A redesign of the IQMS is therefore recommended. A new model could be based on specified competences, with unambiguous criteria, and reliable ratings. Giving continuous and quality performance feedback must be emphasised. A consultative and collaborative approach needs to be followed when redesigning the IQMS. These changes are necessary to ensure consistency between the operational form and the purposes of the redesigned performance appraisal system. Only then can the performance data be credible for use in planning relevant professional development programmes for lecturers.

The greatest limitation of this study was the inability to observe performance appraisals due to time constraints and inadequate financial resources. More research on the impact of the IQMS policy in the FET colleges is recommended to gain insights into the strengths and weaknesses of the current model.

\section{References}

Abi Saleh, N. (2008). Effective management of the performance appraisal process in Lebanon: An exploratory study. ProcheOrient,e tudes en management, No.20, 18 pages. Available at: http://www.fgm.usj.edu.lb/files/pdf/a12008.pdf.

Australian Institute for Teaching and School Leadership. (2012). Australian Teacher Performance and Development Framework. Government of Australia-Education Services.

Bach, S. (2000). From Performance Appraisal to Performance Management. Personnel Management: A Comprehensive Guide to Theory and Practice. Vol. 3, pp 241-263.

Banathy, B. \& Jenlink, P. (2001). Systems Inquiry and its Application in Education. In D.H. Jonassen (ed.), Handbook of research for educational communications and technology, (Vol. 1, pp 74-92). Mahwah, NJ: Lawrence Erlbaum Associates.

Beer, M. (1982). Performance Appraisal: Dilemmas and possibilities. Organisational Dynamics. Vol.19, No.9, pp 24-36.

Boachie-Mensah \& Peter Awini Seidu. (2012). Employees' Perception of Performance Appraisal System: A Case Study. International Journal of Business Management Vol. 7 No.2 pp 73-88.

Brown, D.R. and Harvey, D. (2006). An Experiential Approach to Organisational Development. $7^{\text {th }}$ edition. Pearson Education, New Jersey.

Bubb, S. and Earley, P. (2008). From self-evaluation to school improvement: the importance of effective staff development. CfBT Education, Reading.

Daoanis, Liza Estino (2012). Performance Appraisal System: It's Implication to Employees. International Journal of Economics and Management Sciences Vol. 2, No. 3, pp. 55-62.

Department of Education (2005). The Integrated Quality Management System. Government Printers, Pretoria.

Department of Higher Education and Training. 2012. The Green Paper for Post-School Education and Training. Government Printers, Pretoria.

Descombe, M. (2008). Communities of Practices: A research Paradigm for the Mixed Methods Approach. Journal of Mixed Methods Research, Vol.2: pp 270-283. 
Dowling, P.J., Festing, M., and Eagle, A.D. (2008). International Human Resource Management. $5^{\text {th }}$ edition. Cengage Learning EMEA, London.

Evans, L. (2011). The shape of teacher professionalism in England: Professional standards, performance management, professional development and the changes proposed in the 2010 White Paper. British Educational Journal, Vol. 37, No. 5, pp 851-870.

Figazzolo, L. (2013). The use and misuse of teacher appraisal: An overview of cases in the developed world. Education International, Brussels.

Flores, M. A. 2010. Teacher Appraisal in Portugal: The (Im)possibilities of a Contested Model. Mediterranean Journal of Educational Studies, Vol. 15(1), pp.41-60.

Government of South Africa (1998). Employment of Educators Act, (Act No.76 of 1998). Government Printers, Pretoria.

Grobbler, P.A., Warnich, S., Carrell, M.R., Elbert, N.F., Hatfield, R.D. (2002). Human Resource Management in South Africa. $2^{\text {nd }}$ edition. Thomson Learning, London.

Holi Ibrahim Holi Ali, (2012). How Should an Effective Performance Appraisal Be: EFL Teachers' Perspectives. International Journal of Applied Linguistics \& English Literature

Vol. 1 No. 7; pp199-208

Hutchins, C. L. (1996). Systemic Thinking: Solving complex problems. St Louis, MO: Professional Development Systems.

Johnson, R. B., Onwuegbuzie, A.J. and Turner, L. A. 2007. Toward a Definition of Mixed Methods Research. Journal of Mixed Methods Research, Vol.1 pp 112-133.

Macbeath, J. (2012). The Future of the Education Profession. Educational International Research Institute. Leadership for Learning. Cambridge Network.

Magolis, D. (2010). Systems Theory. Available at: https://sites.google.com/site/davidmagolis/the-climb-psu/systems-theory

Messer, R.F. \& Mires, L.A. (2001) Performance Appraisals: A Tool for Employee Development. Retrieved from: www.acec.org/case Inews/publications/2001 june.pdf

Meyer, M. (ed.) (2007). Human Resource Development: An Outcomes-based Approach. $3^{\text {rd }}$ Edition. LexisNexis. South Africa.

Mgijima, N. (2013). Needs-based professional development of lecturers in the Further Education and Training colleges. The Mediterranean Journal of Social Sciences. (in press).

Mgijima, M. N. and Morobe, N. (2012). The Sector Skills Plan for the Public FET Colleges' sub-sector. ETDP SETA, Johannesburg.

Monyatsi, P., Steyn, T. \& Kamper, G. 2006. Teacher perceptions of the effectiveness of teacher appraisal in Botswana. South African Journal of Education, Vol. 26(3), pp 427-441.

Odhiambo, George O., 2005. Teacher appraisal: the experiences of Kenyan secondary school teachers. Journal of Educational Administration, Vol. 43, pp $402-416$.

Pedder, D., Storey, A., \& Opfer, V. (2008). Schools and continuing professional development (CPD) in England - State of the Nation research project. Cambridge University, Open University and TDA.

Proper, C. and Wilson, D. (2003). The Use and Usefulness of Performance Measures in the Public Sector. CPMO Working Paper Series No. 03/073. University of Bristol. Retrieved from: http://www.bris.ac.uk/Depts/CMPO/workingpapers/wp73.pdf

Reigeluth, C., Banathy, B.H. \& Olson,J.R. (1993). Comprehensive systems design: A new educational technology. Berlin: SpringerVerlag.

Smit, PJ, Cronje, G.J., Brevis, T. \& Vrba, M.J., (2007). Management Principles: A Contemporary Edition for Africa. $4^{\text {th }}$ edition. Juta, Cape Town.

Storey, A. (2009). "How fares the New Professionalism in schools? Findings from the State of the Nation project". Curriculum Journal, 20, Vol.2, pages 121-138.

Watson, S.L., \& Reigeluth, C.M. (2008). Community members' perceptions on social, cultural changes and its implication for educational transformation in a small school district community. Journal of Organisational Transformation and Social Change, Vol. 5, No.1, pp 45-65.

Watson, S.L., Watson, W.R. \& Reigeluth, C.M. (2008). Systems Design for Change in Education and Training. Handbook of research on educational communications and technology, pages 691-701.

Walker, M., Jeffes, J., Hart, R., Lord, L. \& Kinder, K. (2011). Making the links between teachers' professional standards, induction, performance management and continuing professional development. Department for Education, United Kingdom 